\title{
СЛОВО О ПЕРЕВОДЕ... (СТИХОТВОРЕНИЯ ДЛЯ ДЕТЕЙ САМУИЛА МАРШАКА МОРОЖЕНОЕ)
}

На страницах проекта о творчестве Фёдора М. Достоевского «Двадцать лет спустя» читаем:

Двадцать лет тому назад были обнаружены факты математических расчётов Достоевского, подтверждавших альтернативный взгляд писателя на русскую литературу и её значение. Достоевский создал виртуальный мир математических, графических образов: «нешлифованный алмаз», «дерево», «гроб», «душа», «портрет»... и другие. Ф.М. Достоевский выступил создателем логико-математической системы, позволяющей достичь невозможного - помочь читателю логически проникнуть в глубину текста и увидеть картины, графические реальные формы и образы. (Filologicheskij proekt)

О том, что математика и литература практически всегда шли рядом, даже странно говорить. Числами и цифрами, датами и расчётами насыщено было уже Святое Писание и библейские тексты.

Великий Леонардо да Винчи создавал прекрасные произведения и занимался математикой, Пифагор сочинял стихи и был великий математик. (...) Но вот скажите кому-нибудь, что А.С. Пушкин был математиком, так вас обругают и назовут сумасшедшим. (Filologicheskij proekt)

А кем является переводчик? Может, выполнение перевода поэтического текста, оригинал которого создан другим человеком, первым

Dr hab. Edyta Manasterska-Wiącek, prof. UMCS - Uniwersytet Marii Curie-Skłodowskiej w Lublinie, Instytut Neofilologii, Katedra Językoznawstwa Słowiańskiego; e-mail: e.manasterska@ poczta.umcs.lublin.pl, edyta.manasterska@gmail.com; ORCID: https://orcid.org/0000-0003-49989668.

${ }^{1}$ Слово о переводе - это тоже заглавие книги Вилена Н. Комиссарова. 
автором - это на самом деле система расчётов и калькуляции, сложений, вычитаний, поиска средств, приводящих к наиболее полному сходству формы текста и его значения с подлинником? Чтобы ответить на этот вопрос, стоит проанализировать примерный перевод с такой точки зрения. Прежде чем перейти к исследованию, ставим следующий существенный вопрос: как переводить для детей? ${ }^{2}$

Этот вопрос в себе уже априори затрагивает две проблемы: способы передачи текста в другую культуру и специфику детского читателя. Кажется, что прежде чем обратить внимание на некоторые проблемы, возникающие в процессе перевода, необходимо, во-первых, остановиться на специфике детского реципиента. В чём же состоит «сложность» такого читателя?

Источником его исключительности является процесс развития человека и неизбежная при таком процессе незрелость, которая проявляется в разных сферах жизни: в языковом аспекте, в области знаний, в жизненном опыте. На всех этих уровнях ребёнок развивается. Теоретиками детского развития выдвигается проблема различий между взрослыми и детьми. Эти различия с точки зрения психологии и биологии определяются пятью категориями: поведение, знания, физиологические особенности, степень самостоятельности и мера ответственности (Enciklopediya otlichij). Особо подчёркивается также проблема эмоций малышей.

Эмоциональная сфера ребёнка раннего возраста является центральной в системе психических свойств. (...) Ребёнок спонтанен и импульсивен, а также неустойчив и лабилен в выражении своих эмоциональных состояний и переживаемых им в данный момент чувств. (Kamenskaya 125-126) ${ }^{3}$

Именно для такого читателя переводится произведение. Литература является мощным стимулятором развития ребёнка. Не существует единой теории, как переводить для детей, но своего рода подсказкой является учесть их отличие от взрослых, зрелых читателей. Подвижность эмоциональных реакций связана также с восприятием слов, при помощи которых пишутся поэтические образы. Как замечает В.Г. Каменская: «ребёнок воспринимает социальный и предметный мир не таким, каким он является на самом деле, а таким, каким ему хочется его видеть»

\footnotetext{
${ }^{2}$ Существует довольно много научных работ, посвящённых теме перевода для детей, однако в настоящей статье мы занимаемся единичным случаем перевода и не будем к ним обращаться (см. например: Oittinen; Borodo; Liseling-Nilsson; Manasterska-Wiącek).

${ }^{3}$ CM. Manasterska-Wiącek.
} 
$(126)^{4}$. Большое значение имеет факт, что дети понимают речь дословно. Если к этому добавить неограниченные возможности создания ими образов и более развитое, чем у взрослых, воображение, тогда каждое слово и выражение имеет особое значение.

Для того, чтобы подробно обсудить проблему значения слов в потенциальном восприятии их детьми, рассмотрим конкретный перевод. Источником нашего исследования является стихотворение Самуила Маршака Мороженое $e^{5}$ и его перевод на польский язык, выполненный Янушем Минкевичем ${ }^{6}$. Это в какой-то мере нетипичное стихотворение. Хотя структура определённых фрагментов текста повторяется, возникает впечатление, что оно имеет нерегулярное строфическое строение, длина строк меняется и влияет на ощущение ритма. В стихотворении появляются парные, перекрёстные и кольцевые рифмы. Все качества, присущие стихотворению, перед выполнением перевода должен учесть переводчик, всё принять во внимание, всё «подсчитать»- как математик.

\section{КОГДА ПЕРЕВОДЧИК \\ СТАВИТ ЗНАК ТОЖДЕСТВЕННОСТИ [三]}

Знак тождественности в переводе не означает полного сходства между словами, словосочетаниями или предложениями в текстах подлинника и перевода. Тождественность касается уровня восприятия произведений читателями.

Исследуемое стихотворение - это история дедушки, который везёт крашеный сундук и продаёт мороженое. Вокруг него собираются дети, радуются лакомству. Вдруг подходит толстяк и начинает бесконтрольно его есть до тех пор, пока не превратился в снежную гору, с которой катается детвора. Но гора не снежная, а из мороженого.

Посмотрим на эти фрагменты, которые передаются без особенных изменений:

Мы, ребята, босиком

Ходим вслед за сундуком.

4 Эмоции и чувства младшего школьника см. Volkov 85-90; основные закономерности психического развития ребёнка см. Volkov и Volkova 58-95, Berdnikova 37-52, словесные ассоциации Frumkina 189-206.

${ }^{5}$ Marshak, Skazki, piesni, zagadki.

${ }^{6}$ Marszak, Przygody Reksa-Kleksa. 
Остановится сундук -

Все становятся вокруг.

(...)

Взял мороженщик лепёшку,

Всполоснул большую ложку,

Ложку в банку окунул,

Мягкий шарик зачерпнул,

По краям пригладил ложкой

И накрыл другой лепёшкой.

Зачерпнул десяток раз.

- Получайте свой заказ!

Biegną dzieci bosonogie,

Zabiegają lodom drogę,

Póki wózek nie przystanie...

- Teraz będzie używanie!

(...)

Wielką łyżkę chwycił lodziarz,

Spłukał ją starannie w wodzie,

Potem czystą, opłukaną,

W bańkę zanurzył blaszaną;

Wyjął stamtąd lodów kulę,

Przygładziwszy kulę czule,

Włożył ją w wafelki dwa...

- Drugą porcję niech pan da - [Я.M.7]

Стихотворение «Мороженое» впервые было издано в 1925 г. Нет ничего странного в том, что дети бегали тогда босиком по улице, наверное, в коротких рубашонках ${ }^{8}$. Перевод Минкевича соответствует той картине мира, а читатель чувствует радость и забаву детей. Исследование анализируемого перевода в наше время даёт возможность посмотреть на него с точки зрения современного читателя. Исторические реалии в тексте Маршака - это останавливающаяся в разных пунктах маленьких городков и деревень громыхающая тележка-сундук с мороженым, дедушка-продавец и конечно же способ еды десерта - на улице

\footnotetext{
7 Януш Минкевич.

8 «В 1295 году Марко Поло привез в Европу рецепт неизвестного тогда десерта, для охлаждения которого использовали не только снег и лед, но и селитру. Продукт в формочке помещался в воду (затем в воде растворялась селитра) или в лед вместе с солью. После этого внутреннюю и внешнюю формы начинали вращать, что способствовало более быстрому замораживанию продукта без образования крупных кристаллов». Первое ванильное мороженое придумал французкий кулинар, Жерар Тирсен в 1649 г. (См. «Istoriya morozhenogo»).
} 
ложечкой на блюдечках. К этим историческим элементам принадлежит и мороженое, которое на улице вкладывали между лепёшками. Отдельные элементы такой картины мира существуют и в наши времена, но не в таких же соотношениях. Мы встречаем на улицах холодильники с мороженым, но, редко бывает, что продают его пожилые люди. Едим на тарелках холодные десерты, но в кофейнях, а между лепёшками они покупаются в готовом виде. Трудно менять историю, выполняя перевод, тем более, что ребёнок должен знакомиться с прошлым. Тем не менее, остался один элемент целой структуры, который безусловно вызовёт совершенно другие ассоциации - это босые дети. Даже в прошлом ребёнок без обуви не принадлежал к высшим слоям общества, сегодня же это однозначный признак нищеты. Бывает, конечно, что дети в жаркий день бегают босиком, но только перед домом и не по проезжей части улицы. Кажется, что примерно такой перевод (автора статьи) не вызывал бы подобных ассоциаций:

Wszystkie dzieci, tak jak stały,

Za tym wozem w mig pognały.

Aby stanął - już wesoło!

Zaraz wianek dzieci wkoło. [Э.M.B.] $]^{9}$

Приведённый фрагмент подлинника представляет также эмоциональный образ работы мороженщика, в которую он вкладывает свои чувства, сердце. Без всякого сомнения, эти эмоции удачно переданы Минкевичем, хотя со стороны структуры текста наблюдается и некая потеря. В одной фразе перевода произошло искажение ритма - чтобы поддержать постоянную ритмику, нужно поставить неправильное ударение и нарушить языковую норму:

Potem czystą, opłukaną,

W bańkę zanurzył blaszaną.

Однако каждое стихотворение читается лучше без такого типа ошибок. В качестве примера приводим наш перевод, в котором сохраняется постоянная рифма:

Wziął wafelki lodziarz stary

I łyżeczkę też do pary.

\footnotetext{
${ }^{9}$ Перевод наш - Эдита Манастерска-Вионцек.
} 
Nabrał z góry i ze spodu, Zrobił ładną kulkę z lodów, Potem między wafle włożył, Kulkę w środku nich ułożył,

Rzucił na nią swe spojrzenie:

Proszę! Pana zamówienie. [Э.M.B.]

Сопоставление этих переводов с оригиналом приводит к существенному наблюдению - текст Минкевича в приведённом отрывке заканчивается иначе, чем подлинник. «Математический анализ» ведёт нас к очередному расчёту.

\section{КОГДА ПЕРЕВОДЧИК ОТНИМАЕТ [-]}

Переводчик «Мороженого» отнимает, и отнимает довольно много. После того, как старичок тщательно накладывает мороженое, переводчик резко сокращает историю. Не останавливается на описании, как толстяк быстро пожирает десерт, только переходит к его следующему заказу. Такое описание, конечно, оказывает влияние на читателя или, скорее, не имеет возможности повлиять на него, поскольку лишает адресата контакта с данным образом:

(... и накрыл другой лепёшкой)

Зачерпнул десяток раз.

- Получайте свой заказ!

Не моргнул толстяк и глазом,

Съел морожное разом,

А потом кричит опять:

- Дай ещё на двадцать пять

Да в придачу на полтинник -

Я сегодня именинник!

(...) włożył ją w wafelki dwa..

- Drugą porcję niech pan da -

Krzyknął grubas - z tej przyczyny,

Że dziś moje imieniny! [Я.M.]

И наш перевод:

(Potem między wafle włożył,

Kulkę w środku nich ułożył, 
Rzucił na nią swe spojrzenie:

Proszę! Pana zamówienie.)

Tłuścioch prawie w okamgnieniu

Zjadł te lody stojąc w cieniu.

Krzyczy znowu: - Do roboty!

Nałóż mi za 10 złotych!

No i dodaj jeszcze krztyny,

Bo mam dzisiaj imieniny! [Э.M.B.]

Перед процитированным фрагментом, а после того, как босые дети радуются своими десертами, Маршак повторяет начало стихотворения:

По дороге - стук да стук -

Едет крашеный сундук.

Затем переходит к описанию, откуда летом взялся лёд и как во время пути разговаривают друг с другом банки:

Летним утром в сундуке

Едет зимний холод -

Синий лёд, что на реке

Был весной расколот.

Банки круглые по льду

Тараторят на ходу.

От стоянки до стоянки

Разговаривают банки.

Этих фрагментов читатель перевода вообще не испытывает - они не переведены. Из-за такого решения Минкевич предоставляет своему читателю сильно редуцированный образ. Поскольку этой части в переводе нет, посмотрим на его примерный - наш - перевод:

Kolorowy wózek mały

Tur tur tur turkocze cały.

Latem w wozie kolorowym

Jechał sobie chłód zimowy.

Śnieżny lód, co wiosną z rzeki

Był wykuty w kaflach wielkich.

Od przystanku do przystanku

Tłuką się już o poranku

Lodowate pojemniki.

Słychać ich lodowe krzyki! [Э.M.B.] 
В подлиннике замечается интересный подбор слов - не случайно появляются почти все названия времён года. Этого лишён читатель перевода Минкевича. Следует помнить, что художественная литература выполняет не только эмоциональную, развлекательную, но и познавательную функции. Перед переводчиком стоит сложная задача передать то, что влияет на развитие ребёнка, даже если это всего лишь представленные нами нюансы. Решение опустить существенные фрагменты текста в переводе возникает в замысле его автора, а творческое воображение переводчика не всегда тождественно с общей идеей автора текста. Если это происходит без серьёзных оснований, выбор переводчика трудно оправдать.

В приведённых примерах видны и звукоподражательные слова, которые передают звук сундука. Они появляются в оригинальном стихотворении два раза:

По дороге - стук да стук -

Едет крашеный сундук.

Старичок его везёт,

На всю улицу поёт.

С точки зрения детского читателя подобные элементы текста имеют важное значение. Ребёнок почти слышит, как едет сундук с мороженым, а слова, способствующие таким ощущениям, стоит переводить. Посмотрим на перевод Минкевича (который, в противоположность оригиналу, не повторяет этого фрагмента):

Starszy człowiek jezdnią kroczy

I przed sobą wózek toczy.

Pcha go wolno wzdłuż ulicy

I zza wózka głośno krzyczy. [Я.M.]

И наш перевод:

Kolorowy wózek mały

Tur tur tur turkocze cały.

Jedzie wolno po ulicy,

Stary lodziarz głośno krzyczy. [Э.M.В.]

Это не единственный пример приёма редукции в переводе Минкевича, не единичное «математическое отнимание» им целых образов в тексте. Возвращаясь к нашим босоногим ребятишкам, для того чтобы 
детский читатель мог «почувствовать вкус» мороженого, Маршак строит прекрасную, наполненную эмоциями, картину:

(все [дети] становятся вокруг.)

Сахарно

Морожено

На блюдечки

Положено,

Густо и сладко,

Ешь без остатка!

Дали каждому из нас

Узенькую ложечку,

И едим мы целый час,

Набирая всякий раз

С краю понемножечку.

А как передаёт эту картину Минкевич?

(Teraz będzie używanie!)

Lodziarz lody w wafle wkłada -

Każdy porcję swoją zjada. [Я.M.]

Перед глазами польского читателя вообще не появляется солнечная, живая, почти праздничная картина счастливых детей, которые наслаждаются вкусным мороженым. Переводчик резко ограничивает эмотивность приведённой части стихотворения и связанное с ней возможное эмоциональное восприятие читателем.

Мы попытались передать все потерянные элементы исследуемой картины:

(zaraz wianek dzieci wkoło)

Słodkie

Zabajone

Na talerzyk nałożone

Jaka słodka gratka,

Zjemy do ostatka!

Za jedną chwileczkę

Każdy ma łyżeczkę

I godzinę zajadamy,

Lody z talerzyków

Po troszeczku nakładamy. [Э.M.B.] 
Сопоставление обоих текстов позволяет заметить, что переводчик, изменяя наполнение стихотворения образами в одном месте, добавляет их в другом.

\section{КОГДА ПЕРЕВОДЧИК ПРИБАВЛЯЕТ [+]}

В подлиннике Маршак четыре раза - после частей текста, в которых кто-то ест мороженое (дети и толстяк) - перечисляет его вкусы. Эти фразы приводят к собственной ритмической комбинации, отличаясь от остальных строф:

(на всю улицу поёт:)

- Отличное

Земляничное

Мороженое!...

(...)

- Ради ваших именин

Получайте, гражданин,

Именинное,

Апельсинное

Мороженое!

(...)

- Ради вашего рожденья

Получайте угощенье -

Прекрасное

Ананасное

Мороженое!

(...)

Катит в саночках народ.

Под полозьями не лёд,

А клубничное,

Земляничное,

Именинное

Апельсинное

Мороженое!

Стоит обратить внимание, что столбик вкусов постепенно становится в стихотворении Маршака всё длиннее. В последнем примере дети не едят мороженое, а на нём катаются. И это одновременно последняя часть стихотворения, существенная с точки зрения детского реци- 
пиента. На обросшем льдом толстяке устроилась забава, дети начали восхищаться безумным развлечением. Минкевич переводит текст как бы независимо от этой картины и авторских решений:

(i zza wózka głośno krzyczy:)

Doskonałe,

Niebywałe,

Owocowe,

Poziomkowe,

Malinowe,

Truskawkowe,

Cytrynowe

LODY!

(...)

- Aaa, winszuję panu szczerze,

Wobec tego, niech pan bierze

Doskonałe,

Niebywałe,

Owocowe,

Poziomkowe,

Malinowe,

Truskawkowe,

Cytrynowe,

Ananasowe,

Pomarańczowe,

imieninowe

LODY!

(...)

Tylko jeżdżą nie po lodzie,

Lecz... po lodach truskawkowych! [Я.M.]

Компенсируют ли переводческие прибавления упомянутые ранее потери? В обоих текстах царит радость, но, независимо от этого, Минкевич как бы не понял, не прочувствовал забавную неслучайную структуру приёма повторения (они становятся всё длиннее) и, прежде всего, авторскую идею целостной организации текста. Многочленное перечисление, накопление рифмованных прилагательных, называющих каждый раз отдельные вкусы мороженого, кажется избыточным и приводит к совсем другим ощущениям. Придаёт тексту иную окраску и воссоздаёт отличающийся от подлинника эффект. Хотя мороженое в качестве снега нетипично, незивисимо от вкуса лакомства, нагромождение и смешение вкусов в виде снега, показанное в конце текста - это суть развлечения детей: нельзя ведь забывать о детском воображении. 
Передача авторского представления в переводе оказалась довольно несложной:

Stary lodziarz głośno krzyczy:

- Wyborowe,

Poziomkowe

Lodowe!

(...)

- Skoro to są imieniny,

To życzenie twe spełnimy:

Imieninowe,

Pomarańczowe

Lody wyborowe!

(...)

- Skoro to są urodziny,

To życzenie twe spełnimy.

Całkiem nowe

Ananasowe

Lody wyborowe!

(...)

Śmiechów i radości w bród,

Choć pod nimi nie ten lód,

A truskawkowe,

Poziomkowe,

Imieninowe,

Pomarańczowe,

Lody wyborowe! [Э.M.B.]

Здесь стоит обратить внимание на интересное явление, а именно, несоответствие существительных для обозначения еды и материала для катка в русском и польском языках. «Мороженое» - это 'замороженное сладкое кушанье', лёд - 'замёрзшая и перешедшая в твёрдое состояние вода'. То, что соединяет в языке подлинника оба слова - это холод. В польском языке на базе упомянутых значений легко используется игра слов, поскольку lody - это кушанье, существительное, принадлежащее к разряду pluralia tantum и lód - состояние воды. Следует добавить, что пользователи польского языка употребляют в разговорном стиле существительное lody в единственном числе (например: Kupisz mi loda? Chce tylko jednego loda.), что приводит к квазиомонимическим формам (lód - состояние воды и lód - кушанье). В обоих случаях в языке перевода - как при употреблении правильных форм, 
так и при нарушении языковой нормы, кроме ассоциации с холодом, отмечается также близость (или даже тождественность) существительных по звучанию.

\section{КОГДА ПЕРЕВОДЧИК ИСПОЛЬЗУЕТ ПРИБЛИЖЁННОЕ РАВЕНСТВО [ح]}

Автор перевода «Мороженое» прибегает в определённых фрагментах и к неточной передаче истории, указанной в подлиннике. Трудно ожидать буквального перевода текста, но рассмотрим, насколько такое решение влияет на его потенциальное восприятие.

Толстяк кушает мороженое, покупая десерт, а потом получает его в подарок на именины и на день рождения, хотя оба этих праздника, вероятно, вымысел толстяка. В переводе же он лжёт только один раз, когда говорит только о своём дне рождения.

Приблизительность видна и в передаче последней картины стихотворения. Толстяк съел столько мороженого, что преобразовался в снежную гору, зато в переводе - в снеговика:

А толстяк молчит - не слышит.

Ананасным паром дышит.

(...)

Он стоит и не шевелится, А кругом шумит метелица...

Как у нашего двора

Нынче выросла гора.

Вся дорога загорожена,

Катит в саночках народ.

Под полозьями не лёд,

А клубничное,

(...) [мороженое]

Ale grubas nic nie słyszy, Truskawkową parą dyszy,

(...)

Takie zimno z niego bucha,

Że już każdy w dłonie dmucha.

Wkoło zamieć niesłychana:

Grubas zmienił się w bałwana...

I przy śnieżnym tym bałwanie 
Zamiast wózka jeżdżą sanie.

Krążą w takim samym chłodzie,

Jak za mroźnych dni zimowych,

Tylko jeżdżą nie po lodzie,

Lecz... po lodach truskawkowych! [Я.M.]

Приблизительный перевод - это относительно часто используемый Минкевичем приём. Ребёнку нужно представить точное описание ситуации и это переводчик делает, но по-своему. Толстяк превращается в снежную гору, вокруг которой на санках катаются дети - такую картину ставит перед глазами читателя автор оригинала. У Минкевича это не гора, а снеговик. В детском воображении, наверное, гора - это значительная возвышенность, намного больше снеговика, к тому же гора в тексте Маршака разновкусная, значит и разноцветная, зато снеговик это три снежных шара с чертами, типичными для лица человека глазами из угольков, морковью в качестве носа, ведёрком на голове и т.д. Кроме того, он в тексте Минкевича красный или розовый, как клубничное мороженое. Это, несомненно, разные картины. Переводчик нарушает главный смысл окончания стихотворения, ввиду чего лишает своих читателей возможности увидеть картину из подлинника.

В нашем переводе мы попытались немножко ближе передать смысл оригинала:

Tłuścioch milczy - nic nie słyszy.

Ananasem z lodów dyszy.

Kulki śniegu na ramionach,

Czapka bielą przyprószona.

Stoi thuścioch w tym bezruchu.

Zamieć $w$ jednym, w drugim uchu,

Aż powstała góra cała!

Sanek tyle nie widziała!

Gawiedź wnet się rozszalała,

Śmiechów i radości w bród,

Choć pod nimi nie ten lód,

A truskawkowe (...)

Lody wyborowe! [Э.M.B.]

Подытожим наши рассуждения. «Математические расчёты» появились в нынешнем исследовании только в качестве метафоры некоторых переводческих решений. Поэтический дух произведения, возбуждающий чувства читателя, невозможно свести к простым суммам или 
разностям, хотя они показывают, чем и в какой степени перевод отличается от оригинала. Намного более важным является другой уровень исследования, а именно, к чему приводит перечисленный ряд изменений. Каждый отдельный перевод всегда требует особого, индивидуального подхода - перевод Мороженого также заставляет нас задуматься над причинами и последствиями описанных решений.

По нашему мнению, трудно говорить о полном успехе перевода Минкевича. Почему? Переносное значение математического прибавления или отнимания ни в одном случае не означало поиска дословности передачи слов и выражений, а скорее сопоставимого восприятия читателями текстов перевода и оригинала. Неслучайно, говоря о сопоставимости, мы ставим на первое место перевод - он должен «стремиться» передать картины, которые будут выражать схожую с текстом оригинала эмоциональность, вызывать аутентичные эмоции. Ведь перевод - это никогда не буквальный перенос отдельных элементов текста. В случае перевода поэтического текста, в котором значительную роль играет форма, ограничивающая языковые возможности переводчика, дело ещё более осложняется. Говоря о рецепции поэтического текста, непременно следует помнить об особенностях детского читателя - его эмоциональности, деликатности, чувствительности и исключительности.

Отдельные картины, составляющие в целом представленную автором историю, рисуются в воображении ребёнка. Каждый элемент поэтического рассказа имеет свой локус в таком представлении и каждый влияет на его целостный образ. Перестановка локусов, удаление некоторых из них и добавление новых рисует несколько отличающуюся картину и оказывает иное воздействие на читателя. Это ведёт к другому восприятию и представлению последовательности картин, возникающих в воображении адресата.

Хотя любой перевод - это не математический расчёт, тем не менее, он является результатом последовательного выполнения его автором многочисленных операций. К тому же это специфические операции, в которых в «подведении итога» сложение - не всегда даёт больше, а вычитание не в каждом случае означает меньше. Если такие решения изменяют текст, но не изменяют рецепцию текста и не модифицируют её, они в конечном результате, с точки зрения читателя, означают ноль операции. Это своеобразный парадокс.

Переводчик берёт на себя большую ответственность. Он отображает чужое предположение, передаёт не свой текст, не свою историю. 
Изменения в переводе можно продолжать бесконечно - авторский замысел пишет картины разными красками. Однако нельзя забывать, что замысел рассказанной истории, замкнутой в определённую форму, первоначально принадлежит автору подлинника. Замысел переводчика ограничивается - или должен ограничиваться - именно этой идеей.

\section{БИБЛИОГРАФИЯ}

Berdnikova, Yulia [Leonidovna]. Mir rebenka. Razvitiye psikhiki. Strakhi. Sotsial'naya adaptatsiya. Itnerpretatsiya detskogo risunka. Nauka i Tekhnika. Nauka i Tekhnika, 2007 [Бердникова, Юлия [Леонидовна]. Мир ребёнка. Развитие психики. Страхи. Социальная адаптация. Итнерпретация детского рисунка. Наука и Техника, 2007].

Borodo, Michał. "Children's literature translation studies? - zarys badań nad literaturą dziecięcą w przekładzie". Przekładaniec, nr 16, 2006, ss. 12-23.

Enciklopediya otlichij, Chem vzroslyj otlichayetsa ot rebionka [Энциклопедия отличий, Чем взрослый отличается от ребенка], https://thedb.ru/items/Chem-vzroslyj-otlichaetsja-otrebenka/. Dostęp 20.08.20.

Filologicheskij proekt o tvorchestve F.M. Dostoyevskogo «Dvadcat' let spustia» [Филологический проект о творчестве Ф.М. Достоевского Двадцать лет спустя, https:// arxiv22. wixsite.com/20-let. Dostęp 21.08.20.

Frumkina, R[evekka] M[arkovna]. Psikholingvistika. Akademiya, 2007 [Фрумкина, Р[евекка] М[арковна]. Психолингвистика. Академия, 2007].

«Istoriya morozhenogo». Zanimatelnaya fizika [«История мороженого». Занимательная физика.фp, www.afizika.ru/zanimatelniestati/169-isroriyamorozhenogo. Dostęp 08.08.2019.

Kamenskaya, V[alentina] G[yeorgiyevna]. Detskaya psikhologiya z elementami psykhofiziologii. Forum, 2011 [Каменская, В[алентина] Г[еоргиевна]. Детская психология $c$ элементами психофизиологии. Форум, 2011].

Liseling-Nilsson, Sylvia A. Kod kulturowy a przekład. Na podstawie wybranych utworów Astrid Lindgren $i$ ich polskich przekładów. Acta Universitatis Stockholmiensis. Stockholm Slavic Studies 41, Stockholm University, 2012.

Manasterska-Wiącek, Edyta. Dyfuzja i paradyfuzja w przekładach literatury dla dzieci. Wydawnictwo Uniwersytetu Marii Curie-Skłodowskiej, 2007.

Marshak, S[amuil] Y[akovlevich]. Skazki, piesni, zagadki. Detgiz, 1961 [Маршак, С[амуил] Я[ковлевич]. Сказки, песни, загадки. Детгиз, 1961].

Marszak, Samuił. Przygody Reksa-Kleksa. Tłum. Julian Tuwim, Seweryn Pollak, Jan Brzechwa, Konstanty Ildefons Gałczyński, Janusz Minkiewicz, Wanda Grodzieńska, Włodzimierz Boruński, Czesław Janczarski, Mieczysława Buczkówna, Leopold Lewin. Nasza Księgarnia, Warszawa, 1965.

Oittinen, Ritta. I am me - I am other: on the dialogics of translation for children. University of Tempere, 1993. 
Volkov, B[oris] S[tepanovich]. Psikhologiya mladshego shkol'nika. Akademicheskij Proekt. Alma Mater, 2005 [Волков, Б[орис] С[тепанович]. Психология младшего школьника, Академический проект. Альма Матер, 2005].

Volkov, B[oris] S[tepanovich], \& N[ina] V[yacheslavovna] Volkova. Vozrastnaya psikhologiya. Vlados, 2010 [Волков, Б[орис] С[тепанович] и Н[ина] В[ячеславовна] Волкова. Возрастная психология. Владос, 2010].

\section{SŁOWO O PRZEKŁADZIE... (WIERSZA DLA DZIECI LODY SAMUIŁA MARSZAKA)}

\section{Streszczenie}

Niniejszy artykuł został poświęcony analizie przekładu wiersza Samuiła Marszaka Mopoженое (Lody). Autorka, zastanawiając się nad czynnością przekładu, zadaje na wstępie pytanie, czy działanie owo nie jest pewnym przemyślanym systemem obliczeń - odejmowania, dodawania pewnych treści, ich tożsamości czy równości w porównaniu do oryginału. Próbuje też znaleźć odpowiedź na pytanie, jak tłumaczyć dla dzieci. Czy rzeczywiście odejmowanie istotnych treści w przekładzie, dodawanie nowych w stosunku do tekstu wyjściowego nie stawia czytelnika wobec poważnie zmodyfikowanych czy nawet zupełnie innych obrazów? Kwestionując sensowność niektórych rozwiązań translatorskich analizowanego przekładu, autorka proponuje swój kontrprzekład, szukając możliwości bliższego i, jej zdaniem, bardziej adekwatnego przekazu nie tylko treści, ale i formy tekstu wyjściowego. Co istotne, poszukiwanie równości wobec tekstu oryginału nie jest dążeniem do dosłowności, ale do stworzenia czytelnikowi, poprzez uważne i przemyślane rozwiązania, warunków do podobnej potencjalnej reakcji odbiorczej. Każdy element tekstu ma swój lokus w wyobraźni czytelnika. Zamiana ich miejsc, usuwanie, dodawanie może modyfikować odbiór. Jak się okazuje, „matematyczne działania” w tekście nie zawsze jednak zmieniają odbiór - paradoksalnie odjęcie czy dodanie może oznaczać tożsamość w odbiorze.

Słowa kluczowe: tłumaczenie; przekład dla dzieci; dziecko jako odbiorca; modyfikacja odbioru.

\section{A WORD ON TRANSLATING... (THE CHILDREN'S POEM MOROZHENOYE BY SAMUIL MARSHAK)}

S u m m a ry

The aim of this article is to analyse the translation of Samuil Marshak's poem Morozhenoye ("Ice-cream"). While reflecting upon the process of translation, the author poses the question whether the translator's activity is not a certain conscious system of calculations - adding or subtracting pieces of data, their identity or equity in relation to the original. The author also tries to answer the question of how to translate literary works for children. Isn't subtracting or adding vital pieces of content in the translation process actually putting the reader in front of largely modified or completely different images? While questioning the applicability of some of the translator's solutions in the analysed text, the author proposes her own translation, which aims to reflect the original more closely and more adequately in terms of both content and form. More importantly, seeking equation with the original text is not an attempt to apply word-for-word equivalence, but rather aims at giving the reader the conditions to make a similar reaction to the text, via the translator's conscious and considerate choices. Each piece of the text has its locus 
in the reader's imagination. Replacing, deleting or adding them may modify the text's reception. As it turns out, "mathematical calculations" in the text do not always result in a change in its reception - quite paradoxically, subtraction or addition may result in the most appropriate reception.

Keywords: translation; translation for children; child as recipient; modification of reception. 